\title{
Cortázar, García Márquez, Fuentes y Vargas Llosa: trayectorias de escritura desde el neoindividualismo.
}

\section{Cortazar, García Marquez, Carlos Fuentes y Mario Vargas Llosa: Writing Careers from the Neo-individualism.}

\author{
Claudia Macías de Yoon \\ Universidad Nacional de Seúl (COREA DEL SUR) \\ CE: $\underline{\text { maciascl@snu.ac.kr ID ORCID: 0000-0002-6602-9135 }}$
}

DOI: $10.32870 /$ sincronia.axxiii.n76.18b19

(C) $\mathrm{BY} \cdot \mathrm{NC}$

Esta obra está bajo una Licencia Creative Commons Atribución-NoComercial 4.0 Internacional

Recibido: 26/02/2019

Revisado: 07/03/2019

Aprobado: 18/05/2019

\section{RESUMEN}

Este artículo revisa la relación entre ideologías y literatura en los escritores clásicos del Boom hispanoamericano: Julio Cortázar, Gabriel García Márquez, Carlos Fuentes y Mario Vargas Llosa, enfocándose en el análisis de sus declaraciones, sus posiciones ideológicas y en algunas de sus obras, más allá del contexto revolucionario de Cuba que propició la discusión iniciada por Óscar Collazos, en 1969. Desde la premisa teórica de Gilles Lipovetsky sobre el "neoindividualismo", este estudio pretende demostrar que cada escritor seguía siempre y en primer término sus propios objetivos en su trayectoria, los cuales variaban según las circunstancias sociopolíticas e ideológicas, no obstante haber sido nombrados por unanimidad como los cuatro más representativos del Boom.

Palabras clave: Compromiso y escritura. Polémica. Lipovetsky. Boom. 


\begin{abstract}
:
This article reviews the relationship between ideologies and literature in the classic writers of the Latin American Boom: Julio Cortázar, Gabriel García Márquez, Carlos Fuentes and Mario Vargas Llosa. We will focus on the analysis of their statements, on their ideological positions and of some of their works, all this beyond the revolutionary context of Cuba that gave rise to the discussion started by Óscar Collazos, in 1969. Following Gilles Lipovetsky's theoretical proposal on the "neo-individualism", this study aims to demonstrate that each writer always followed, and in the first term, his own objectives in his career which were changing according to the sociopolitical and ideological circumstances, even though that they had been unanimously appointed as the four most representative writers of the Boom.
\end{abstract}

Keywords: Commitment and writing. Controversy. Lipovetsky. Boom.

\title{
Introducción
}

Óscar Collazos a los 26 años era ya director del Centro de Investigaciones Literarias de Casa de las Américas de Cuba, cuando publicó el artículo "La encrucijada del lenguaje" en dos números de la revista Marcha (Montevideo) de 1969, en contra de los escritores que abandonaban el realismo y las circunstancias históricas de la época. En 2019, se cumplen cincuenta años de esa polémica sobre la relación de la literatura, y de los escritores en particular, con la Revolución cubana. Julio Cortázar y Mario Vargas Llosa respondieron al cuestionamiento de Collazos reflexionando acerca del papel de la literatura y de la responsabilidad del escritor con su realidad. En ese mismo año de 1969, Julio Cortázar dio una entrevista para Life que coadyuvó al enfrentamiento con José María Arguedas. En 1971, el caso Padilla acabaría por dividir a los intelectuales latinoamericanos que parecían un todo indisociable bajo el célebre nombre del Boom.

Nos ocuparemos en este estudio de revisar la polémica iniciada por Collazos como punto de partida para analizar la relación entre ideología y escritura en cuatro autores canónicos: Julio Cortázar, Gabriel García Márquez, Carlos Fuentes y Mario Vargas Llosa. Pero el objetivo de nuestra investigación va más allá del contexto revolucionario de Cuba que propició la discusión en los 
setenta. Nos interesa revisar la relación entre ideologías y literatura en los cuatro clásicos hispanoamericanos, sus declaraciones y posiciones ideológicas que entran en conflicto como intelectuales y escritores, para proponer que cada uno seguía su propia trayectoria aun cuando habían sido nombrados por unanimidad como los cuatro más representativos del Boom latinoamericano. Ángel Rama (1986b, p. 264) revisa las diversas listas que circulaban en su momento para concluir que había "sólo cinco sillones y ni uno más, [...]. De ellos, cuatro son, como en las academias, 'en propiedad': los correspondientes a Julio Cortázar, Carlos Fuentes, Mario Vargas Llosa y Gabriel García Márquez". El quinto quedaba libre para otorgarlo a quien desearan los estudiosos. Pero el crítico destaca ya las diferencias en las trayectorias de dichos escritores, proponiendo el caso de García Márquez: "De hecho es él la prueba de la arbitrariedad con que se ha formalizado el criterio de boom, al cual sólo pertenece por su éxito popular" (Rama, 1986b, p. 284).

Se ha señalado el importante papel de las editoriales españolas en la conformación del Boom, en especial, "Seix Barral [que] estaba tras los pasos de la nueva novela en lengua castellana, sin saber a ciencia cierta si ella existía ni dónde se encontraba." (Espósito, 2009, p. 5). Carlos Barral (2000, p. 79) afirmaría en Caracas sobre lo impreciso del fenómeno de la nueva narrativa latinoamericana: "Creo que el llamado boom no es un hecho de la historia literaria, sino de la historia editorial de la edición en lengua española". También se ha destacado que otro factor determinante en la unión del grupo fue el trabajo de Carmen Balcells como agente literaria: "el papel del agente tuvo y tiene para ellos, una fascinación inolcultable. El agente visto como administrador eficiente y ancilar -gestor de gestores- de la élite." (Catelli, 2010, p. 723), concluyendo que el vínculo fue más profesional y editorial antes que literario: "sobre todo en la continuidad administrativa -no literaria- de esta élite" (Catelli, 2010, p. 726). Sin embargo, también dicho factor tiene su excepción en Cortázar que nunca estuvo adscrito a la agencia Balcells mientras vivió y que sus libros comenzaron a publicarse en España hasta mediados de los setenta, salvo Ceremonias publicado en Barcelona en 1968 (De Diego, 2009, p. 7). 
Por su parte, Mabel Moraña (2013, p. 43) coincide en su estudio comparado de la obra de Arguedas y Vargas Llosa, en el protagonismo de los cuatro escritores de nuestro artículo. Pero además los relaciona con una nueva vía de cosmopolitismo:

El impacto de corrientes europeas y norteamericanas abre una oferta de cosmopolitismo [...]. Cuando este cosmopolitismo se traduzca en los destellos tecnologizados y comercialistas del boom esta opción, que no sería la de Arguedas, se afirmaría como la línea de fuga más prometedora y eficaz para eludir las limitaciones y menoscabos de lo local. (Moraña, 2013, p. 204)

En términos de la interpretación de nuestro estudio, consideramos la propuesta de Gilles Lipovetsky sobre el neoindividualismo. Lipovetsky (2003, p. 44) observa -en la sociedad francesa en especialque "[d]urante los años sesenta y setenta, la ética se consideraba falsa conciencia, una ideología pequeñoburguesa, mixtificada y mixtificadora", al tiempo que destaca el surgimiento de una "cultura 'mosaico', discontinua" (Lipovetsky, 2003, p. 118), la cual había resumido en su premisa del neoindividualismo: "el neoindividualismo significa el desgajamiento de las normas y los comportamientos tradicionales, el derrumbe de las ideologías revolucionarias y nacionalistas" (Lipovetsky, 2000, p. 35).

En este contexto, cabe nuestra propuesta de que los cuatro grandes del Boom tuvieron en primer lugar sus propias líneas y proyectos de escritura y como intelectuales, los cuales fueron variando según las circunstancias históricas y sociopolíticas en que se vieron inmersos. En el caso de Vargas Llosa, revisaremos además su particular postura ante lo mítico-religioso desde la autodeclaración como agnóstico que ha mantenido siempre. Todo ello, como veremos, bien cabe en la afirmación de Lipovetsky (2003, p. 28): “Hoy cada cual desea ser autónomo y construye libremente, a la carta, su entorno personal”, porque como destacara el sociólogo y filósofo francés: "Desde hace medio siglo, consumo y comunicación de masas han puesto en órbita la 'segunda revolución individualista', marcada por el fracaso de los grandes sistemas ideológicos, [...] por el culto a la autonomía subjetiva." (Lipovetsky, 2003, p. 104). 


\section{La polémica por la Revolución}

En 1969, Óscar Collazos inicia la famosa polémica sobre la relación de la literatura latinoamericana con la Revolución cubana. En artículos del 30 de agosto y 5 de septiembre de la revista Marcha, comenzaba criticando una narrativa que pretendía "concebir la literatura como ejercicio autónomo del contexto sociocultural y político [...], lavándose una supuesta conciencia histórica y responsabilidad intelectual" (Collazos, 1970a, p. 7), y aludía directamente la influencia de la Revolución cubana en ese momento: "En el plano sociopolítico [...] somos un contienente en revuelta porque la revuelta es imposible entre los antiguos colonizadores" (Collazos, 1970a, p. 8). Atacaba directamente a Vargas Llosa por su declaración en una entrevista que se le hizo en México, en abril de 1969. El escritor peruano había afirmado: "la literatura no puede ser valorada por comparación con la realidad. Debe ser una realidad autónoma, que existe por sí misma" (Collazos, 1970a, p. 9). El crítico colombiano veía en esta declaración "una peligrosa actitud de mistificación" (Collazos, 1970a, p. 9) y se pronunciaba en contra de dicha mistificación: “la importancia de la novela latinoamericana, tanto dentro como fuera del continente, está precisamente en esta comunión íntima de la realidad con el producto literario" (Collazos, 1970a, p. 11). Señalaba como ejemplo la novela que le diera a Vargas Llosa el premio Biblioteca Breve en 1962: "no se puede creer que La ciudad y los perros sea una novela excelente por la invención milagrosa de otra realidad, de otro mundo inconfrontable" (Collazos, 1970a, pp. 19-20). Para el crítico colombiano, dicha novela valía por la relación "casi marital entre la escritura, las estructuras narrativas y los momentos objetivados por la experiencia del autor" (Collazos, 1970a, p. 20).

En respuesta al enjuiciamiento anterior, Vargas Llosa (1970, p. 80) calificó a Collazos de "fraile medieval cazador de brujas" y dijo a favor de su postura: "sólo afirmo que en el acto de la creación hay la intervención de un factor irracional que muchas veces trastorna y contradice las intenciones y las convicciones del escritor" (Vargas, 1970, p. 84, cursivas nuestras). Y terminaba afirmando que el acto de la creación "se nutre simultáneamente, en grados diversos en cada caso, [...] de dos fases de la personalidad del creador: la racional y la irracional, las convicciones y las 
obsesiones, su vida consciente y su vida inconsciente" (Vargas, 1970, p. 82). Presentaba como modelo a Goethe: "Yo pienso que esos elementos inconscientes, obsesivos, que he llamado los 'demonios' de un escritor (antes lo hizo Goehte, ¿no?), son los que determinan casi siempre los 'temas' de una obra" (Vargas, 1970, p. 82). Pero antes había formulado una pregunta que retomaremos en el apartado correspondiente al Nobel peruano: “¿es posible y deseable que haya una identidad total entre la obra creadora de un escritor y su ideología y moral personales?" (Vargas, 1970, p. 81). Dicha pregunta se respondería con la premisa destacada por Lipovetsky sobre la época en que surge el neoindividualismo: "La época posmoralista coincide con el eclipse y la deslegitimización de las morales colectivas sacrificiales" (Lipovetsky, 2000, p. 40).

De igual forma, Collazos (1970a, p. 10) criticó a Julio Cortázar por obras como 62, modelo para armar y La vuelta al día en ochenta mundos, a causa "[d]el distanciamiento cada vez más radical de la realidad y su banalización, el olvido de lo real circundante". Julio Cortázar respondió que Collazos hablaba de una realidad inmediata, producto de la influencia de la Revolución cubana, y le advertía del peligro de caer en el concepto de 'realismo socialista':

A Collazos le interesa una realidad que cabría llamar inmediata, tiene buen cuiado de no caer en el vocabulario que llevó a la noción y a las consecuencias del "realismo socialista", pero en su manera de entender la función del narrador latinoamericano se transparenta una concepción de la literatura asaz análoga a la que tantas tensiones y problemas creó y crea dentro de las sociedades socialistas. (Cortázar, 1970, p. 50)

Cortázar (1970, p. 73) señaló que "la novela revolucionaria no es solamente la que tiene un 'contenido' revolucionario sino la que procura revolucionar la novela misma", desplazando el problema ideológico a un plano meramente estético. De ahí que antes haya dicho que la realidad era el hombre mismo: "La auténtica realidad es mucho más que el 'contexto sociohistórico y político', la realidad soy yo y setecientos millones de chinos, un dentista peruano y toda la población latinoamericana" (Cortázar, 1970, pp. 64-65), defendiendo a su colega desde ese concepto de realidad: "La realidad autónoma a que alude Vargas Llosa [...] es ese laboratorio en el 
que un novelista opera la revolución en su propia esfera, la revolución en la palabra y la forma y la narración misma." (Cortázar, 1970, p. 74), con lo cual rebatía el cuestionamiento de Collazos a la vez que se confirmaba en dicha postura estética. Paradójicamente, en 1965, Cortázar había confesado a Vargas Llosa (1968, p. 85) sobre sus primeros libros: "Yo no sé dónde empieza o termina lo real y lo fantástico".

Collazos (1970a, p. 10) atacaba a Carlos Fuentes denunciando que "desde Zona Sagrada hasta Cambio de Piel" eran obras que también se inscribían en esa narrativa de fuga de la realidad, orientada a convertir la literatura en un juego o en un rito. Y arremetía de nuevo en la respuesta a Cortázar firmada en La Habana: "según Fuentes, la hora de la novela latinoamericana está marcada por Sears, por los public-relations, los self-service, los enlatados, coca-cola, el artificio del consumo, única posibilidad de aprehensión de lo latinoamericano" (Collazos, 1970b, p. 106). Carlos Fuentes nunca respondió. Las características consignadas, según la cita, estarían marcando otro punto de vista del fenómeno del Boom por parte de los propios escritores que viene a coadyuvar a nuestro objetivo de estudio.

El único escritor que se salvó de la crítica del colombiano fue Gabriel García Márquez, citado pero para recibir alabanzas. Incluía la declaración de García Márquez sobre su poética realista -"Yo creo que particularmente en Cien años de soledad yo soy un escritor espantosamente realista, porque creo que en América Latina todo es posible, todo es real"- (Collazos 1970a, p. 28), para luego justificar dicha declaración citando al prestigiado crítico del Boom:

Hace solo unos meses, en Bogotá, en charlas informales con Ángel Rama, me llamaba la atención el interés del crítico uruguayo por la realidad política de Colombia [...], todo ese mundo de factores estaban profundamente tratados en Cien años de soledad. Bastaba remitirnos a la historia, ejercer un acto de confrontación con la realidad colombiana. (Collazos, 1970a, p. 30)

Muchos años después, Collazos (2014) declararía quién había sido el autor intelectual de dicha polémica: “El 29 de agosto de 1969 (día de mi cumpleaños) [...] por petición de Ángel Rama, 
publiqué en Marcha de Montevideo, un ensayo sobre la novela latinoamericana, las ideas políticas de los escritores y la función de estos en los fenómenos revolucionarios de la historia".

\section{Julio Cortázar en Life y otras polémicas}

Martín de Ambrosio (2004) registra que "al menos cuatro fueron las polémicas en las que Cortázar se vio envuelto". La primera, a fines de los sesenta, contra José María Arguedas. El conflicto se podría resumir en la postura cosmopolita de Cortázar, frente al escritor peruano que defendía los valores del pueblo y la cercanía con sus raíces culturales. Arguedas (1987) lo acusa en el "Primer diario" fechado el 15 de mayo de 1968, de El zorro de arriba y el zorro de abajo: "Y había decidido hablar hoy algo sobre el juicio de Cortázar respecto del escritor profesional. Yo no soy escritor profesional, Juan [Rulfo] no es escritor profesional [...]. Soy en ese sentido un escritor provincial; sí, mi admirado Cortázar" (p.25).

Julio Cortázar le responde en la entrevista que le hiciera Rita Guibert para el número 33 de la revista Life, con el título "La órbita de Julio Cortázar" según aparece en Papeles inesperados, no obstante que en la cubierta de dicha revista se anunciaba como "Julio Cortázar. El hombre en el escritor" (Cortázar, 1969b). La entrevista dice:

[...] ni Arguedas ni nadie va a ir demasiado lejos con esos complejos regionales. [...] A Arguedas le fastidia que yo haya dicho [...] que a veces hay que estar muy lejos para abarcar de veras un paisaje, que una visión supranacional agudiza con frecuencia la captación de la esencia de lo nacional. (Cortázar, 2009, p. 255)

La aceptación de dicha entrevista para Life "resultaba incongruente con su postura [...] aunque justificó que había exigido el derecho de revisar las pruebas para comprobar que lo dicho por él se respetaría con puntos y comas, antes de su publicación en abril de 1969” (Macías, 2016, p. 33). Fue, sin duda, "una incursión en territorio ideológicamente minado" (Vallejo, 2014, p. 27). Y resultaba incongruente porque en 1965 había enviado una carta a Roberto Fernández Retamar donde afirmaba su devoción por el Che Guevara: "Me emocionó todo lo que me dices del Che, porque lo 
comparto plenamente. En marzo saldrá en Buenos Aires un nuevo tomo de cuentos míos, donde irá naturalmente el que escribí después de leer las páginas del Che sobre el desembarco con Fidel." (Cortázar, 1965, p. 25). Life intituló el texto de Cortázar “Un gran escritor y su soledad” (Cortázar, 1969b, p. 43), con una foto del autor caminando de espaldas por París.

Arguedas le respondería también indirectamente, invocando a Roberto Fernández Retamar en el "Tercer diario", fechado en Santiago de Chile el 18 de mayo de 1969:

[...] desde la grandísima revista norteamericana Life, Julio Cortázar, que de veras cabalga en flamígera fama, como sobre un gran centauro rosado, me ha lanzado unos dardos brillosos. Don Julio ha querido atropellarme y ningunearme, irritadísimo, porque digo en el primer diario de este libro, y lo repito ahora, que soy provinciano de este mundo, que he aprendido menos de los libros que en las diferencias que hay, que he sentido y visto entre un grillo y un alcalde quechua. (1987, p. 143).

La polémica no concluyó nunca. Cortázar siempre lamentó no haber resuelto esta disputa al enterarse del suicidio del escritor peruano y seguramente más lo habría sentido de haber conocido la confesión que le hiciera Arguedas a Ariel Dorfman, amigo común, por su dolor de no haber sido comprendido en su escritura: "'Si no puedo escribir, mejor es no estar vivo'. En efecto, había completado su novela con su propia muerte", agregaría Dorfman (2011). El escritor argentino había afirmado en otra de sus numerosas cartas a Fernández Retamar:

El que mis libros estén presentes desde hace años en Latinoamérica no invalida el hecho deliberado e irreversible de que me marché de la Argentina en 1951, y que sigo residiendo en un país europeo que elegí sin otro motivo que mi soberana voluntad de vivir y escribir en la forma que me parecía más plena y satisfactoria. Hechos concretos me han movido en los últimos años a reanudar un contacto personal con Latinoamérica, y ese contacto se ha hecho por Cuba y desde Cuba; pero la importancia que tiene para mí ese contacto no se deriva de mi condición de intelectual latinoamericano; al contrario, me apresuro a decirte que nace de una perspectiva mucho más europea que latinoamericana, y más ética que intelectual. (Cortázar, 1967, pp. 59-60, cursivas nuestras) 
En esa misma carta, había criticado a la revista Life: "argentinos de mi generación que comulgan todos los días con las ruedas de molino subliminales de la United Press y las revistas 'democráticas' que marchan al compás de Time o de Life" (Cortázar, 1967, p. 61, comillas del texto), de ahí que sintiera la necesidad de justificarse ante sus amigos cubanos por su colaboración de años después:

Quiero ahora decirte dos palabras sobre un asunto que olvidé comentarte allá, aunque tenía la intención de hacerlo. [...] Hace dos meses, Life en Español me buscó para hacerme una entrevista. [...] En este tiempo de malentendidos frecuentes, me interesa que estés enterado de esto, que lo estén Haydée y todos los amigos de Casa. (Cortázar, 1969a, p. 85)

Gracias a la respuesta de José María Arguedas que lo critica por publicar en Life, queda en evidencia dicha publicación -que constituiría otra polémica- con la cual se pone de manifiesto que la perspectiva de Cortázar ya era "más europea que latinoamericana" y que respondía a una ética muy personal, como había afirmado en 1967. Gilles Lipovetsky (2000, p. 40) destaca: "La devoción a la patria ha dejado de ser un valor que se enseñe y se exalte".

La tercera polémica fue con Osvaldo Bayer que le pidió que se comprometiera ante la dictadura que sufría Argentina bajo Videla: “Bayer le propone a Cortázar encabezar un chárter de intelectuales en vuelo sorpresivo a Argentina y Cortázar se excusó -dice Bayer-porque andaba muy enamorado de Carol Dunlop, su última mujer, y además temía que le metieran un balazo en la cabeza" (De Ambrosio, 2004). La escritora argentina Ana María Ramb (2011, p. 109) cuenta cómo la idea de Bayer sobre la delegación de intelectuales que llegaría a Buenos Aires "el día en que el dictador Videla le transfe[ri]ría el mando al dictador Viola, [estaría] encabezado por Julio Cortázar, el grupo denunciaría el horror de la dictadura desde la capital de la Argentina". La propia escritora formaba parte del grupo de intelectuales que los recibiría: "el proyecto de Osvaldo surgía como un faro en la tempestad" (Ramb, 2011, p. 110), la Sociedad Argentina de Escritores estaba al tanto de dicha iniciativa. Pero Ramb señala la cancelación del proyecto de Osvaldo Bayer al que se había sumado el también escritor argentino, Osvaldo Soriano: "me enteré que el proyecto de los dos 
Osvaldos con Cortázar no podía ser" (Ramb, 2011, p. 110). Su juicio contra Cortázar se expresa al contar que lejos de desalentarse siguió participando en otros proyectos contra la dictadura, "de esos que saben organizar con obstinación los compañeros de fierro" (Ramb, 2011, p. 110).

El rechazo a participar en la idea de Bayer lo registra también Miguel Herráez. El biógrafo señala que habían aceptado viajar autores del prestigio de Günter Grass, pero sobre Cortázar dice: "él rechazó" (Herráez, 2011, p. 290). Según incluye la declaración del propio Bayer, Cortázar respondió al rehusarse: "'Yo no quiero que me peguen un tiro en la cabeza' [...] pero después nos explicó que él ya estaba haciendo mucho por Latinoamérica, que estaba trabajando mucho en Nicaragua, Guatemala y en México, y que realmente no quería abandonar ese trabajo." (Herráez, 2011, p. 290). En el neoindividualismo, "[y]a no se hace un llamamiento a los individuos a dar la vida por la patria" (Lipovetsky, 2000, p. 40). Gracias al dato del cambio de poder, nos ubica en fechas cercanas al 29 de marzo de 1981, cuando Roberto Eduardo Viola asume de facto la presidencia.

La siguiente polémica fue contra Liliana Heker en 1979, donde le cuestionó entre otros reclamos que Cortázar se presentara como exiliado político cuando no lo era, ya que había salido hacia París en 1951, sin que nadie lo persiguiera (De Ambrosio, 2004). Su diferencia generacional casi treinta años menor que Cortázar- no le impidió encararlo sobre su autonombrado exilio, “Heker cuestionó que Cortázar se apropiara de la identidad de exiliado. Para Heker, cuando Cortázar inventó su exilio, lo hizo para asumir una identidad que ponderaba como prestigiosa per se." (Jensen, 2005, p. 191). Cortázar le responde señalando que la verdadera escritura de resistencia en contra de la dictadura se escribe desde fuera, por el problema de la censura. Pero en Argentina se interpretó de manera diferente su postura:

Desde París, Cortázar enarbola con sus buenas intenciones un pensamiento que parece provenir del unitarismo liberal. La literatura argentina válida es la del exilio, sostiene. En la simplificación Cortázar no advierte que, a pesar de la dictadura, en el país se escribe una resistencia. Con este argumento, Heker le sale al cruce a Cortázar. (Saccomanno, 2004) 
José Luis de Diego registra que el cuestionamiento que Heker hiciera a Cortázar se extendía también a otros escritores, entre los que menciona se encuentran dos más del Boom: "Desde numerosas publicaciones como Crisis, las preguntas a Cortázar -a García Márquez, a Vargas Llosa y otrossiempre rondaban el mismo tema: si un intelectual puede comprometerse con los procesos revolucionarios sin estar en el país". (2007, p. 51).

Se ha afirmado que "Julio Cortázar fue durante muchos años un hombre casi invisible dentro del campo literario, era un escritor de culto, valorado por muy pocos lectores" (Ferro, 2007, p. 28), y se ha destacado también que fue de los favorecidos por la atención mediática que le dio el Boom.

Igualmente, se debe recordar que no pocos escritores pusieron en tela de juicio el problema de la relación de su obra con su pensamiento. Empezando por José Revueltas que cuestionó el concepto de realidad de Cortázar:

A mí me gusta mucho Sábato, me parece un escritor extraordinario. Tiene mucho más contenido que Cortázar, quien se dispara un poco con la técnica, exagerando los recursos comunicativos cuando podían ser mucho más simples. Yo no estoy en contra de ninguna innovación técnica, pero sí estoy en contra de las actitudes no justificadas sobre la materia que se trata. (Tejera, 2001, p. 51)

\section{Carlos Fuentes, Contra Bush}

Carlos Fuentes no le responde a Óscar Collazos en 1969, ni a José María Arguedas en 1971 cuando lo describe despectivamente en un diálogo hipotético con Juan Rulfo: "Carlos Fuentes es mucho artificio, como sus ademanes." (Arguedas, 1987, p. 21), ni cuando lo critica por su profesionalización:

La última vez que vi a Carlos Fuentes, lo encontré escribiendo como a un albañil que trabaja a destajo. Tenía que entregar la novela a plazo fijo. Almorzamos, rápido, en su casa. Él tenía que volver a la máquina. Dicen que eso mismo le sucedía a Balzac y a Dostoievski. Sí, pero como una desgracia, no como una condición de la que se enorgullecieran. [...] ¿No es natural que nos irritemos cuando alguien proclama que la profesionalización del novelista es un signo de progreso, de mayor perfección? (Arguedas, 1987, p. 26) 
Tampoco era de los favoritos de Ángel Rama. En 1964, al compararlo con José Donoso, denota su desprecio por el entonces joven Fuentes:

Fondo de Cultura Económica ha asegurado el conocimiento de uno de los jóvenes, Carlos Fuentes (35 años hoy), cuando Zig Zag no ha sido capaz de asegurar el alcance continental de un novelista dotadísimo como lo es el chileno José Donoso (Coronación). [...] Esta situación absurda se complica más cuando hay de por medio razones políticas. (Rama, 1986a, p. 28)

Su perfil como escritor profesional, tendencia que seguirían no pocos escritores del Boom, molestaba a los escritores comprometidos con la Revolución cubana y a Rama en particular. Posiblemente se sumaba el hecho de que su rival, Emir Rodríguez Monegal (1963, p. 144), lo hubiera reconocido: "Pocos escritores hispanoamericanos de su generación han tenido la carrera brillante de Carlos Fuentes. [...] En este momento, Fuentes es uno de los pocos novelistas hispanoamericanos que puede vivir de su obra".

La crítica definió a Carlos Fuentes como "un joven mundano y cosmopolita, [...] uno de los personajes más desenvueltos de nuestra literatura" (Harss, 1966, p. 343), que cobraba mil dólares por cada entrevista que concedía (Fortson, 1973, p. 56). La profesionalización de Fuentes coincide con "las instituciones y la economía liberales [que] hacen posible la superación de las fronteras nacionales" (Lipovetsky, 2000, p. 35), en una sociedad más abierta a la movilidad profesional o geográfica.

Su compromiso con la Revolución nunca quedó de manifiesto. Por el contrario, llegó a afirmar:

[...] creo que independientemente de la Revolución cubana, nunca he visto el porqué de esta insistencia en ligar el famoso Boom literario de los años sesenta con la Revolución cubana. [...] Si puedo decirlo de una manera muy personal, yo publiqué un libro de mucho éxito, La región más transparente, antes de la Revolución cubana. (Marras, 1992, p. 59) 
En el primer número de la revista Mundo Nuevo editada por Rodríguez Monegal, acusada por Ángel Rama -con el respaldo de Casa de las Américas- de ser financiada por la CIA (Gilman, 1996, p. 13, n.1), Carlos Fuentes (1966, p. 8) declara en entrevista: “Günter Grass y Norman Mailer, y Andy Warhol y Susan Sontag, y Joan Baez y Bob Dylan, ¿verdad? Para mí este es el mundo que cuenta, el mundo que me interesa realmente". En la misma entrevista, se refiere a los escritores que se realizan como tales fuera de sus países:

[...] yo también pienso que hay un momento en que una literatura existe y va adelante gracias a sus emigrados. No es gratuito que los dos escritores latinoamericanos más importantes de este momento sean Octavio Paz y Julio Cortázar que son dos personas que, además de su talento, tienen esta enorme perspectiva frente a sus países y frente a la cultura latinoamericana. (Fuentes, 1966, pp. 8-9)

Resulta de interés la definición de Fuentes, en la década de los sesenta y en pleno periodo del Boom, sobre la permanencia en el extranjero de los escritores, ya que nunca piensa en el concepto del exilio, como lo proclamaba Cortázar.

En cuanto a Octavio Paz, Fuentes perdió el aprecio que le tenía por razones ideológicas y políticas. En 1967, Paz (1987, p. 592) había alabado La región más transparente derivando el elogio a su autor: "les descubrió a un joven escritor que desde entonces no cesaría de asombrarlos, desconcertarlos e irritarlos". Pero el Nobel mexicano terminaría rechazándolo, junto a García Márquez, por su relación con Fidel Castro: “'Octavio Paz, que ha dirigido las jornadas, calificó a los dos escritores de apologistas de tiranos y añadió: Hay que aprender a decir y a escuchar la verdad: hay que criticar tanto el estalinismo de Neruda como el castrismo de García Márquez'." (El País, 1990). Sin embargo, la acusación le deviene de su amistad con el Nobel colombiano. Fuentes había roto con la Revolución desde que firmara la carta fechada en París el 20 de mayo de 1971 (Vargas, 2009, p. 118), exigiendo a Castro la libertad de Heberto Padilla. No obstante, Julio Ortega (2008, p. 16) señala que “[p]or más de veinte años su nombre estuvo en la 'lista negra' del Departamento de Estado norteamericano, prohibido de ingresar a los Estados Unidos". 
Aquí comentaremos en particular un libro que se quedó sin incluir en la autoclasificación de sus obras Ilamada La Edad del Tiempo (Macías, 2014, p. 72), se trata de Contra Bush. Julio Ortega (2008, pp. 35-36) recopila incompleta dicha clasificación, ya que contiene solo hasta el apartado XV. Un artículo más reciente relata el origen de la idea y hasta su clausura con Federico en su balcón, señalando que se trataba de un mural "formado por las novelas y los libros de cuentos de Fuentes, escritos y por escribir" (García-Gutiérrez, 2016, p. 75). Pero Fuentes dividía en veinte apartados su obra, el XIX dedicado a los libros de ensayos bajo el título de "Ensayos en el tiempo"; el último título que incluía era En esto creo (2002).

Si nos atenemos al solo título, Contra Bush, sería de aplaudir su valor. El propio autor hace el prólogo y se presenta como "observador mexicano y latinoamericano de la crisis política norteamericana y global provocada por la administración de George W. Bush" (Fuentes, 2004, p. 9). Subtítulos como "Bush de cal y de arena", "El peor Presidente", "Los Estados Unidos, su propio enemigo" convencerían a cualquier lector del compromiso político de Fuentes plasmado en su escritura. Sin embargo, la duda se deja sentir desde las primeras páginas: "la paradoja consiste en que los extraordinarios éxitos de la administración Clinton entre 1992-2000, se reviertan a favor del contrincante republicano, George W. Bush" (Fuentes, 2004, p. 15). El elogio al predecesor continúa en ascenso, "Bill Clinton deja la presidencia de los Estados Unidos con una altísima popularidad [...]. Los logros de Clinton son impresionantes" (Fuentes, 2004, p. 23); “¿Dónde estás, Bill Clinton, cuando más te necesitamos?" (Fuentes, 2004, p. 38, cursivas nuestras); "La clara conciencia de los límites del poder imperial [...] distinguió a la presidencia de un verdadero estadista, Bill Clinton" (Fuentes, 2004, p. 78); "la verdad central enunciada por un gran estadista y un gran presidente, Bill Clinton" (Fuentes, 2004, p. 104); "Bill Clinton cumplió sus inevitables obligaciones como jefe de la superpotencia con una discreción, capacidad negociadora y convocatoria a alianzas totalmente ajenas al escándalo maniqueo" (Fuentes, 2004, p. 119). A la par, aparecen los denuestos para Bush: "Carente de ideas propias, Bush se deja influir por su entorno con gran facilidad" (Fuentes, 2004, p. 74); “Bush no es Hitler ni Stalin. Pero tiene más poder que ellos. Este es el peligro." (Fuentes, 2004, p. 105). 
La postura ideológica del escritor mexicano no es contra el sistema capitalista representado por los Estados Unidos, sino contra el presidente Bush en particular al que insulta hasta el extremo de llamarlo "un presidente borracho de ideología religiosa" (Fuentes, 2007). Julio Ortega (2008, p. 73) defendió en cierta forma este libro, al señalar: "en su alegato Contra Bush (2004), la crítica se presenta como la articulación actual entre lo local y lo internacional, entre la cultura de la región y el mundo multipolar". Aunque señala después acerca del carácter independiente de Carlos Fuentes: No ha hecho un grupo y no se debe ni a partidos ni a ideologías; no responde por los poderes del Estado pero tampoco por los poderes del mercado. Ha elevado, en ese sentido, la práctica de la literatura a las responsabilidades de su independencia solidaria. (Ortega, 2008, pp. 15-16)

La afirmación de Julio Ortega, crítico y amigo personal de Carlos Fuentes, está en consonancia con la idea de Lipovetsky (2000, p. 35) acerca de "un tipo de individualidad de tendencia flexible, sin adhesiones profundas, más escéptica, más pragmática". William M. LeoGrande y Peter Kornbluh (2015) cedieron a La Jornada una foto para ilustrar su artículo, donde se aprecia a Carlos Fuentes al lado de Hillary y Bill Clinton, acompañados de otros amigos. Esa muestra de amistad entre el presidente tan aclamado con el escritor bien podría justificar un libro como Contra Bush.

\section{Gabriel García Márquez y "La muñeca tetona”}

Carmen Balcells felicita a Gabriel García Márquez por sus 85 años de vida leyendo un fragmento de "Muerte constante más allá del amor", el cuento preferido de su agente literaria. Llama la atención que sus razones sean por su precisión estilística y por la universalidad de sus imágenes:

"Al senador Onésimo Sánchez le faltaban seis meses y once días para: morirse cuando encontró a la mujer de su vida". Este fragmento lo recuerdo siempre. Y a veces solo recuerdo yo a García Márquez porque es imposible en tan poco espacio dar una imagen a cualquier lector de cualquier rincón del globo, un escandinavo, un alemán, una señora de la provincia de Lérida como podría ser yo, en estado puro. Entonces, al leer esto, en tres palabras él se sitúa en lo es ese senador Onésimo Sánchez. Y el hecho de decir que le faltaban seis meses y 
once días para morir es una cosa que a mí siempre me ha dejado completamente trastocada, porque es tan ilustrativo y sobre todo, para morir cuando encontró a la mujer de su vida. Y el cuento que es un cuento sencillo, divino, cuenta lo que es la mujer de su vida. (Manrique, Sánchez, Almodóvar, 2012, la transcripción es nuestra)

García Márquez aparece también en la foto citada de Bill Clinton con Carlos Fuentes. Clinton dijo del Nobel: "Tuve el honor de ser su amigo y de conocer su gran corazón y mente brillante durante más de 20 años" (El Comercio, 2014). Los testimonios se quedaron en las numerosas fotos que circulan de ambos por todo el mundo. Simultáneamente, la relación del escritor colombiano con Fidel Castro estaba fuera de duda. Viajaba cada verano hacia La Habana donde lo esperaba el Comandante listo para abandonar los pantalones largos y descansar al lado de su entrañable amigo, como se aprecia en la foto de la cubierta de Gabo y Fidel. El paisaje de una amistad (Esteban y Panicheli, 2004). A Gabriel García Márquez no le encontramos ningún libro dedicado a Clinton, aunque sí consideró a Fidel Castro en un lugar especial de sus memorias, Vivir para contarla.

La pregunta sobre García Márquez sería ¿qué hacía en tantas fotos con presidentes de distintas ideologías? Nos dedicaremos a una fotografía, tal vez la más polémica, que ha arrastrado una historia que se ha contado en video por los protagonistas, entre ellos, Carlos Salinas de Gortari, expresidente de México. A la foto se le llamó "La muñeca tetona", por la muñeca de trapo que aparece como testigo de la reunión de intelectuales con Salinas. Salinas de Gortari cuenta en el video que Bill Clinton le llamó para pedirle el favor de intermediar con Castro, a causa de la emigración del Mariel:

Decidí llamar a Fidel Castro pero primero le llamé al mejor interlocutor con Fidel. Tomé el teléfono, le marqué a Gabriel García Márquez a su casa [...] y le dije: “Gabriel, me gustaría hablar contigo, ¿podrías venir a Los Pinos?", eran como las nueve de la noche. Era una respetuosa invitación pero había también buena relación. [...] Cuando llegó le expresé lo que había sucedido. Y el Gabo me dijo: "Creo que es mejor que usted le llame directamente al Presidente Castro. Pero -me dijo el Gabo- les voy a avisar en La Habana de esta llamada". Así lo hizo. [...] Y se inició un diálogo entre el Presidente de Estados Unidos y el Comandante 
Fidel Castro, terciado por el Presidente de México, pero con una presencia extraordinaria de Gabriel García Márquez. (Osorno y Aldrete, 2017, la transcripción es nuestra)

En entrevista, Clinton señala que se conocieron en 1994, “durante unas vacaciones en Martha's Vineyard, en Massachusetts" (Gómez, 2014). Justamente de ahí proviene la foto donde sale también Carlos Fuentes; ambos, huéspedes del novelista William Styron. Clinton siempre hizo pública su admiración por el Nobel colombiano. En dicha entrevista, confirma que hablaban sobre la política de Cuba: "Cuando finalmente logramos conversar lo hicimos sobre política y nos enfrascamos en una discusión sobre el embargo a Cuba. Disfruté cada minuto de esa conversación." (Gómez, 2014). No era gratuito que Susan Sontag lo acusara "de deshonestidad intelectual por callar sobre las violaciones de los derechos humanos del régimen castrista. 'Lo siento por García Márquez, pero hay cosas que no se pueden callar'." (El Periódico Francfort, 2003). El escritor le responde a Sontag declarando que había ayudado a gran número de cubanos que necesitaban salir de la isla por su condición de presos políticos: "Yo mismo no podría calcular la cantidad de presos, de disidentes y de conspiradores que he ayudado en absoluto silencio a salir de la cárcel o a emigrar de Cuba en no menos de veinte años." (García, 2003). Pronto escribe otra carta en contra de la manipulación de su "respuesta a Susan Sontag, para que parezca contraria a la revolución cubana" (García, 2003).

¿Sería posible estar a favor del sistema vigente en Cuba sin que se quebrara su relación con Clinton? Su biógrafo registra sus remordimientos por su falta de coherencia ideológica con el socialismo:

Cuando se publicó La hojarasca, justo antes de que dejara Bogotá para irse a Europa, los amigos comunistas de García Márquez habían comentado que, aunque se trataba de un libro excelente [...], la obra adolecía, a su gusto, de un exceso de mito y poesía. García Márquez confesaría tanto a Mario Vargas Llosa como a Plinio Mendoza [...] que había desarrollado un complejo de culpa porque La hojarasca era una novela "que no denuncia, que no desenmascara nada". En otras palabras, la obra no se ajustaba a la concepción comunista de 
una literatura socialmente comprometida que denunciara la represión capitalista e imaginara un futuro socialista mejor. (Martin, 2009)

No solo Sontag le reclamó su indefinición en cuanto a su compromiso político. No pocos le reclamaron su relación con tantos mandatarios de variadas ideologías: "su cercanía con [...] Felipe González, o los exmandatarios de Estados Unidos y Francia, Bill Clinton y Francois Mitterand. Cercanía [...] completamente acrítica en el caso del líder cubano Fidel Castro." (Pérez Salazar, 2014). Jorge Herralde (2005, p. 89), en la sección "Diccionario Bolaño", incluyó la frase con la que el chileno definía a García Márquez: “Un hombre encantado de haber conocido a tantos presidentes y arzobispos".

Guilles Lipovetsky afirma que con el neoinvidualismo aparece la era de "la nueva indiferencia posideológica: poca movilización y motivación políticas en profundidad. La confrontación derechaizquierda subsiste pero pierde su radicalismo anterior." (Lipovetsky, 2000, p. 32).

Para cerrar este apartado, la razón de la admiración de Bill Clinton por el Nobel colombiano podría ayudarnos a definir su carácter: "Porque Gabo marchaba al ritmo de su propio tambor y dedicó su vida a crear memorias que nos estremecerán para siempre." (Gómez, 2014, cursivas nuestras).

\section{Mario Vargas Llosa, ¿agnóstico?}

A Mario Vargas Llosa se le acusa, en 1969, de no ser un escritor realista. El escritor peruano se defiende proclamando una literatura que existe por ella misma, sin necesidad de ceñirse a ningún contexto sociohistórico. En nuestro artículo, no revisaremos cómo justificaría entonces cada una de sus mejores novelas realistas o históricas (¿cómo sería mejor clasificarlas?), ya que sin la dictadura de Trujillo no habría podido escribir La Fiesta del Chivo; sin la existencia de Flora Tristán y de su nieto Paul Gauguin no habría creado El Paraíso en la otra esquina; sin la tragedia de Canudos no habría sido posible La guerra del fin del mundo (2000) y, como le reclamara Óscar Collazos, La 
ciudad y los perros no existiría si no hubiera padecido en su adolescencia esa escuela militar en donde los personajes aparecen configurados hasta con sus nombres reales.

Mabel Moraña ha dedicado un libro entero a revisar el contraste entre Arguedas y Vargas Llosa, de quien señala de entrada que "[s]u narrativa se afinca en el manejo hábil de lenguaje literario desde el encuadre lujoso y comercializado del boom que lo convierte tempranamente en la superestrella de la canonicidad literaria andina" (Moraña, 2013, p. 26). La crítica uruguaya analiza con detalle la serie de fisuras políticas e ideológicas por las que atraviesan las obras de Vargas Llosa, donde menciona "la polémica con Mario Benedetti sobre temas vinculados a la ideología y al papel del intelectual latinoamericano" (Moraña, 2013, p. 35), así como la que enfrentara contra Ángel Rama por su ensayo Gabriel García Márquez: historia de un deicidio, "con mayor radicalidad aún que en el debate de 1969" (Moraña, 2013, p. 212), al que hicimos referencia en el primer apartado.

Aquí nos ocuparemos de un punto que prácticamente ha ignorado la crítica. La repetida declaración de Vargas Llosa como agnóstico. Durante su campaña por la presidencia del Perú, Vargas Llosa afirmó:

Para buen número de mis compatriotas, resultó imposible diferenciar el ateísmo del agnosticismo, por más que, en aquella entrevista, hice cuanto pude para aclarar que un ateo es también un creyente -alguien que cree que Dios no existe- en tanto que un agnóstico se declara tan perplejo sobre la existencia como sobre la inexistencia de un ser divino y de una vida ultraterrena. (1993, p. 127).

En 1982, había declarado: "he sido siempre un agnóstico" (Solares, 1982, p. 27), al inicio del milenio, había confirmado su postura: "Siendo agnóstico, las conversiones religiosas me suelen dejar bastante frío" (Vargas, 2002). Y la reitera en entrevista con Sergio Vilela (2013): "Vargas Llosa, que se declara agnóstico, cuenta que dentro de su casa siempre se practicó la libertad respecto de las decisiones de cada cual sobre la religión y la fe. [...] 'Soy agnóstico, que no es ser un ateo, es ser un perplejo'”. 
Sin embargo y a pesar de su confesión, el elemento religioso cobra singular importancia en obras fundamentales de su trayectoria literaria. El autor reconoce que trabajó con toda conciencia sobre este tema en dos de las novelas que ha señalado entre sus preferidas: La guerra del fin del mundo (2000) y La Fiesta del Chivo. Pero desde La casa verde aparecía ya la presencia de lo religioso.

En La guerra del fin del mundo (2000), el elemento religioso es decisivo en la configuración del universo de la novela: "el Consejero prácticamente no habla nunca, está visto desde lejos, porque me parecía que acercarme al Consejero era como romper el mito." (SETTI, 1989, p. 55). Al final, la última voz cierra la historia con una afirmación acorde con la propuesta mítica y religiosa: “Lo subieron al cielo unos arcángeles -dice, chasqueando la lengua-. Yo los vi" (Vargas, 2000, p. 719). Ignacio Solares destaca la ausencia del factor religioso hasta antes de esta novela, a lo cual Vargas Llosa responde:

-Pienso que la falta del tema religioso en mi obra era una limitación. Ahora aparece y, creo, con una importancia central. Por eso es para mí tan significativa, entre otras razones, La guerra del fin del mundo. Los trabajos de documentación que realicé no sólo tenían relación con Canudos y con el mundo brasileño del siglo pasado, sino también con la experiencia religiosa por sí misma. Comencé haciendo lecturas sobre historia y terminé haciendo lecturas sobre religión, ya por el hechizo mismo que el tema ejercía sobre mí. (Solares, 1982, p. 26, cursivas nuestras)

En sus memorias, Vargas Llosa habla de su relación con Ernesto Alayza Grundy, político peruano de ideología socialcristiana: "don Ernesto me había hecho llegar las encíclicas de la Iglesia sobre el tema social, y sus propios escritos" (Vargas, 1993, p. 126). De otro gran amigo suyo, Lucho Bustamante, señala que mantenía "una muy estrecha amistad con los jesuitas, en cuyo colegio había estudiado, y enseñaba en la Universidad del Pacífico, vinculada a la orden." (Vargas, 1993, p. 129). Vargas Llosa admira el compromiso de los católicos, en especial las actividades promovidas por la Iglesia en el campo social y admira también al personaje histórico Salvador Estrella Sadhalá, a 
quien se refirió como "un hombre profundamente religioso, un católico que trató de vivir [...] absolutamente de acuerdo con los postulados de su fe" (Krauze y Vargas, 2000, p. 24).

Sabine Köllmann (2001, p. 144) comentó sobre La Fiesta del Chivo: "la representación de la fe católica como fuente de vigor moral es un nuevo matiz en la obra de Vargas Llosa". Otro testimonio singular es el ensayo La tentación de lo imposible. Victor Hugo y Los Miserables (2004), en donde Vargas Llosa (2004, p. 205) dedica el penúltimo capítulo a una reflexión en torno a los últimos tiempos de escritura de Víctor Hugo, centrada en el problema de la existencia de Dios: “Para Dios, que es espíritu, importa lo espiritual como realidad dominante, y es en la vida íntima, profunda, impalpable, del alma humana, donde sucede lo que de veras cuenta". La confesión sobre su idea de Dios en relación con el alma humana parece rebasar los límites de un agnóstico.

En su más reciente declaración al respecto de sus creencias, deja lugar a la duda sobre la cuestión de otra vida después de la muerte:

[...] si existe otra vida o no existe, eso no te lo podré decir. Mi inteligencia no me da, no tiene vuelo suficiente para entender cómo podría ser esa otra vida, y de todas las explicaciones que existen ninguna me convence. Ahora, al mismo tiempo, tampoco me convence la afirmación categórica de los ateos de que esa otra vida no existe y que no hay nada y que todo lo que hay aquí es todo lo que habrá. Tampoco mi inteligencia me permite aceptar eso con la seguridad categórica, fanática del ateo. Entonces lo que soy es eso, tengo dudas. [...] Un agnóstico también puede acercarse al final de su vida preguntándose cadónde llego? (Vilela, 2013)

¿Mario Vargas Llosa será realmente tan agnóstico como se proclama? Las conversiones religiosas representadas en La Fiesta del Chivo desde la teología tomista sumadas a la declaración anterior dejan la duda de que no "haya una identidad total entre la obra creadora de un escritor y su ideología y moral personales" (Vargas, 1970, p. 81), como había declarado. Como señala Lipovetsky (2000, p. 35) al respecto: "La era del neoindividualismo instala a la sociedad civil en estado de apertura frente al movimiento histórico, crea mentalidades más dispuestas al reciclaje". La posición 
de Vargas Llosa bien cabría en el contexto que se explicita sobre el neoindividualismo en EI crepúsculo del deber. La ética indolora de los nuevos tiempos democráticos:

En adelante todo no será igualmente legítimo, el neoindividualismo abre un espacio de dispersión de los criterios morales y de juicios diferentes pero no se apoya ya en ningún deber último: la era posmoralista ya no tiene prédica, todavía hay microexclusiones a la carta. (Lipovetsky, 1998, p. 61)

\section{Conclusión}

Los escritores no pueden traicionarse a sí mismos. Tarde o temprano, su escritura, sus declaraciones, sus fotos los evidencian tal y como son. El compromiso del escritor latinoamericano fue una bandera que se usó para anunciar al mundo el nacimiento de una nueva literatura hispanoamericana. Sin embargo, ya en la década de los setenta se da una fuerte crisis por el caso de Heberto Padilla, la cual aprovechan escritores como Mario Vargas Llosa para distanciarse de la Revolución. El Nobel peruano dice a propósito de la carta que firmaron los intelectuales en contra de Fidel Castro: “La iniciativa de esta propuesta nació en Barcelona [...]. Juan y Luis Goytisolo [...] y yo nos reunimos en mi casa y redactamos, cada uno por separado, un borrador. Luego los comparamos y por votación se eligió el mío." (Vargas, 2009, p. 117, 119). La carta fue firmada por más de sesenta intelectuales, entre ellos se encuentran los nombres de Carlos Fuentes y, por supuesto, el de Mario Vargas Llosa, en mayo de 1971. De Gabriel García Márquez era de esperarse que no firmaría. Pero ¿qué sucedió con Julio Cortázar? En la entrevista de mayo de 1975 con Elena Poniatowska (2013, p. 17), el escritor declaró: “En dos palabras, es una historia muy vieja que ya no tiene ningún interés porque se solucionó perfectamente". Cortázar aclaraba que hubo dos cartas y que solo firmó la primera: "La segunda carta que yo no firmé (y esto, Elena, quiero que lo subrayes) fue insolente, malévola y paternalista, en la que los europeos, y muchos latinoamericanos, pretendían darle lecciones a Fidel Castro" (Poniatowska, 2013, p. 18). Sin embargo, Cortázar (2012, p. 54) "a título estrictamente privado" le pediría a Ángel Rama que no incluyera su nota publicada sobre Padilla en el libro que preparaba sobre el poeta cubano; la razón: "ha sido fuente de 
incontables malentendidos en Cuba [...], sería atizar un fuego de equívocos bastante maniqueos y exasperantes en que me ha metido la tendencia cada vez más radical de nuestros cubanos" (Cortázar, 2012, pp. 54-55).

Gabriel García Márquez había dicho a Mario Vargas Llosa: “La desacralización del boom me parece saludable. Ya sabes que ese ha sido siempre mi punto de vista." (Ayén, 2014, p. 527). Catelli (2010, p. 726) destaca que, no obstante el importante papel que jugó España en el surgimiento del llamado Boom, fueron después "los imperalismos modernos, el francés y el inglés, cuyos centros mantuvieron y mantienen un poderoso atractivo intelectual sobre las élites [...] culturales". Ciertamente, París jugó un papel crucial en los escritores que aparecen en "un espacio público cada vez más desideologizado e individualista", como señala Lipovetsky (1998, p. 203) a partir de sus observaciones de la sociedad francesa de los años sesenta y setenta: "toda la esfera de la ciudadanía registra la puesta al día que consagra la preponderancia de los derechos individuales sobre las obligaciones colectivas". Lipovetsky (2000, p. 40) agregaría: "La devoción a la patria ha dejado de ser un valor que se enseñe y se exalte. [...] La época posmoralista coincide con el eclipse y la deslegitimización de las morales colectivas sacrificiales".

Cerraremos esta reflexión con la declaración de Emir Rodríguez Monegal (1984, p. 31), mirando al Boom en retrospectiva:

Do you remember Walter Benjamin's essay “Paris: Capital of the Nineteenth Century"? Well, Paris is really the international capital of Latin America even today. It has lost some ground to New York, but it has the advantage of being a great city where you can still live cheaply. Latin American writers, especially during the sixties, always made their sentimental journey to Paris, and I knew that I could always find talent just outside the door.

[¿¿Recuerdas el ensayo de Walter Benjamin "París: capital del siglo XIX"? Bueno, París es realmente la capital internacional de América Latina, incluso hoy en día. Ha perdido terreno frente a Nueva York, pero tiene la ventaja de ser una gran ciudad donde todavía se puede vivir barato. Los escritores latinoamericanos, especialmente durante 
los años sesenta, siempre hicieron su viaje sentimental a París, y yo sabía que siempre podía encontrar talento justo afuera de la puerta.]

El neoindividualismo, según el filósofo y sociólogo francés, "vuelve a investir la dimensión del sentido de instrumento de edificación personalizada de la existencia. Todo salvo la gratuidad, Narciso es tendencialmente «sensato», es decir, para nosotros, el acecho del "plan», productor «lúcido» de su vida." (Lipovetsky, 1998, p. 71). Lo interesante es que considera positivo este nuevo tipo de individualismo, al agregar a su afirmación de que el neoindividualismo es de tendencia flexible y pragmática:

Eso es de importancia capital para el futuro, porque las sociedades contemporáneas, comprometidas en la competencia internacional, tienen una necesidad imperativa de actitudes flexibles, de mentalidades "desrigidizadas". (Lipovetsky, 2000, p. 35)

Este proceso que la crítica ha visto como característico de los jóvenes escritores contemporáneos, ya se anunciaba en la trayectoria literaria de autores clásicos que se clasificaron como Boom y que la historia literaria sigue manteniendo unidos en la plataforma ideológica que se le adscribió a la nueva novela latinoamericana, como la denominó Carlos Fuentes. Así pues, las posiciones de estos cuatro escritores, Cortázar, García Márquez, Fuentes y Vargas Llosa se mueven según cambian los tiempos, como hemos podido ver en este acercamiento. Como afirma Gilles Lipovetsky (2000, p. 31): "el individuo [y el escritor] posmoderno es el militante de su propia persona".

\section{Referencias}

Arguedas, J. M. (1987). El zorro de arriba y el zorro de abajo. Lima: Horizonte.

Ayén, X. (2014). Aquellos años del boom. García Márquez, Vargas Llosa y el grupo de amigos que lo cambiaron todo. Barcelona: RBA.

Barral, C. (2000). Almanaque. Valladolid: Cuatro Ediciones. 
Catelli, N. (2010). La élite itinerante del boom: seducciones transnacionales en los escritores latinoamericanos (1920-1968). En C. Altamirano (Ed.), Historia de los intelectuales en América Latina. II. Los avatares de la "ciudad letrada" en el siglo XX (pp. 712-732). Buenos Aires: Katz.

Collazos, Ó. (1970a). La encrucijada del lenguaje. En Literatura en la revolución y revolución en la literatura. Polémica (pp. 7-37). México: Siglo XXI.

Collazos, Ó. (1970b). Contrarrespuesta para armar. En Literatura en la revolución y revolución en la literatura. Polémica (pp. 94-118). México: Siglo XXI.

Collazos, Ó. (23 de agosto de 2014). ¿Cómo era Julio Cortázar? Semana. Recuperado de 2018 de http://www.semana.com/Imprimir/400089?PageSpeed=noscript

Cortázar, J. (1965). Carta del 24 de diciembre de 1965. Casa de las Américas, 25 (145-146), 1988, 25-26.

Cortázar, J. (1967). Carta del 10 de mayo de 1967. Casa de las Américas, 25 (145-146), 1988, 59-66.

Cortázar, J. (1969a). Carta del 15 de enero de 1969. Casa de las Américas, 25 (145-146), 1988, 85-86.

Cortázar, J. (1969b). Julio Cortázar: un gran escritor y su soledad. Life en español, 33 (7), 43- 55.

Cortázar, J. (1970). Literatura en la revolución y revolución en la literatura: Algunos malentendidos a liquidar. En Literatura en la revolución y revolución en la literatura. Polémica (pp. 38-77). México: Siglo XXI.

Cortázar, J. (2009). Lo que sigue se basa en una serie de preguntas que Rita Guibert me formuló por escrito... En A. Bernárdez y C. Álvarez (Eds.), Papeles inesperados (pp. 234-258). Madrid: Alfaguara.

Cortázar, J. (2012). A Ángel Rama. En A. Bernárdez y C. Álvarez (Eds.), Cartas 1969-1976 (pp. 54-55), t. 4. Buenos Aires: Alfaguara.

De Ambrosio, M. (8 de febrero de 2004). Cortázar polemista. Página 12. Recuperado de http://www.pagina12.com.ar/diario/suplementos/libros/10-930-2004-02-08.html

De Diego, J. L. (2007). La transición democrática: intelectuales y escritores. En A. Camou, M. C. Tortti y A. Viguera (Eds.), La Argentina democrática: los años y los libros (pp. 49-82). Buenos Aires: Prometeo Libros.

De Diego, J. L. (2009). Cortázar y sus editores. Orbis Tertius, 14(15). Recuperado de http://www.memoria.fahce.unlp.edu.ar/art revistas/pr.4197/pr.4197.pdf 
Dorfman, A. (18 de enero de 2011). Pagando una deuda imposible. El País. Recuperado de 2019 de http://elpais.com/diario/2011/01/18/opinion/1295305204 850215.html

El Comercio (17 de abril de 2014). Bill Clinton dice estar honrado de haber sido amigo de Gabo. El Comercio. Latinoamérica. Recuperado de https://elcomercio.pe/mundo/latinoamerica/billclinton-dice-honrado-haber-sido-amigo-gabo-311442

El periódico Francfort (12 de octubre de 2003). Sontag acusa a García Márquez "por callar cosas que sabe". El Periódico de Aragón. Recuperado de https://www.elperiodicodearagon.com/noticias/escenarios/sontag-acusa-garcia-marquez-porcallar-cosas-sabe 80902.html

Espósito, F. (2009). Seix Barral y el boom de la nueva narrativa hispanoamericana: las mediaciones culturales de la edición española. Orbis Tertius, 14(15). Recuperado de http://www.memoria.fahce.unlp.edu.ar/art revistas/pr.4198/pr.4198.pdf

Esteban, Á. y Panichelli, S. (2004). Gabo y Fidel. El paisaje de una amistad. Madrid: Espasa Calpe.

Ferro, R. (2007). Escritura y vida en los textos de Julio Cortázar/Un modelo para desarmar. Taller de Letras, (41). 21-51.

Fortson, J. R. (1973). Perspectivas mexicanas desde París. Un diálogo con Carlos Fuentes. México: Corporación Editorial.

Fuentes, C. (1966). La situación del escritor en América Latina. Mundo Nuevo, (1). 5-21.

Fuentes, C. (2004). Contra Bush. México: Aguilar.

Fuentes, C. (22 de noviembre de 2007). Bush y Cuba. El País. Recuperado de https://elpais.com/diario/2007/11/22/opinion/1195686004 850215.html

García-Gutiérrez, G. (2016). El mural infinito de Carlos Fuentes. La edad del tiempo. Revista de la Universidad de México. (151). 66-75.

García, G. (29 de abril de 2003). Cartas a Susan Sontag y Carmen Lyta. En Colección de Gabriel García Márquez. The University of Texas at Austin: Harry Ransom Center [texto mecanografiado firmado]. Recuperado de https://hrc.contentdm.oclc.org/digital/collection/p15878coll73/id/28792/ 
Gilman, C. (1996). Intelectuales "libres" o intelectuales "revolucionarios". Política y cultura sobre un campo minado. En Le discours culturel dans les revues latino-américaines de 1970 a 1990 (pp. 11-20). París: América. Cahiers du CRICCAL.

Gómez Maseri, S. (26 de abril de 2014). "Gabo marchaba al ritmo de su propio tambor": Bill Clinton. El

Tiempo. Recuperado de: https://m.eltiempo.com/archivo/documento/CMS-13888316

Harss, L. (1966). Los nuestros. Buenos Aires: Sudamericana.

Herráez, M. (2011). Julio Cortázar, una biografía revisada. Barcelona: Editorial Alrevés.

Herralde, J. (2005). Para Roberto Bolaño. Buenos Aires: Adriana Hidalgo Editora.

Jensen, S. (2005). Vientos de polémica en Cataluña: los debates entre "los de adentro" y "los de afuera" de la Argentina de la última dictadura militar. Revista HMiC, (3). 189-209.

Köllmann, S. (2001). La Fiesta del Chivo: cambio y continuidad en la obra de Mario Vargas Llosa. Iberoamericana (Berlín), (3). 135-149.

Krauze, E. y Vargas Llosa, M. (2000). La seducción del poder. Conversación. Letras Libres, (19). 22-26.

LeoGrande, W. M. y Kornbluh, P. (5 de diciembre de 2015). Diplomacia encubierta con Cuba. La Jornada. Recuperado de https://www.jornada.com.mx/2015/12/05/opinion/a04a1cul

Lipovetsky, G. (1998). El crepúsculo del deber. La ética indolora de los nuevos tiempos democráticos. Trad. Juana Bignozzi. Barcelona: Anagrama.

Lipovetsky, G. (2000). Espacio privado y espacio público en la era posmoderna. Trad. Emilio Duhau. En B. Arditi (Ed.), El reverso de la diferencia. Identidad y política (pp. 23-36). Caracas: Nueva Sociedad. Lipovetsky, G. (2003). Metamorfosis de la cultura liberal. Ética, medios de comunicación, empresa. Trad. Rosa Alapont. Barcelona: Anagrama.

Macías, C. (2014). El magisterio de Carlos Fuentes frente a la crítica. Revista de Letras (Sao Paulo), 54(1), 71-92.

Macías, C. (2016). La influencia de Felisberto Hernández en los cuentos de Julio Cortázar. Revista de Letras (Sao Paulo), 56(1), 31-51.

Manrique, W.; Sánchez, J. y Almodóvar, L. (6 de marzo de 2012). Vídeo de la agente literaria Carmen Balcells felicitando a Gabriel García Márquez en su 850 cumpleaños. El País. Recuperado de https://www.youtube.com/watch?v=V82xhkbJ3oA 
Marras, S. (Ed.) (1992). Carlos Fuentes: viajando en un furgón de cola. En América Latina: marca registrada (pp. 31-65. Barcelona: Ediciones B-Ed. Jurídica de Chile).

Martin, G. $\left(1^{\circ}\right.$ de octubre 2009). Gabo, una vida. Nexos. Recuperado de https://www.nexos.com.mx/?p=13335

Moraña, M. (2013). Arguedas/Vargas Llosa. Dilemas y ensamblajes. Madrid: Iberoamericana-Vervuert.

El País (31 de agosto de 1990). Octavio Paz considera a García Márquez y Carlos Fuentes “apologistas de tiranos". El País. Cultura. Recuperado de https://elpais.com/diario/1990/08/31/cultura/652053604 850215.html

Ortega, J. (2008). Imagen de Carlos Fuentes. México: Jorale Editores.

Osorno, D. E. y Aldrete, A. (2017). La muñeca tetona. Documental. 23 min. Recuperado de 2019 de http://conarte.org.mx/cineteca/la-muneca-tetona/

Paz, O. (1987). La máscara y la transparencia. En Generaciones y semblanzas. Escritores y letras de México (pp. 592-598). México: Fondo de Cultura Económica.

Pérez, J. C. (17 de abril de 2014). García Márquez y su fascinación con el poder. BBC. Recuperado de https://www.bbc.com/mundo/noticias/2014/04/140405 garcia marquez poder ob jcps

Poniatowska, E. (2013). Julio Cortázar. Charlas con el gran cronopio. Revista de la Universidad de México, 116, 17.

Rama, Á. (1986a). La generación del Medio Siglo. En La novela en América Latina. Panoramas 1920-1980 (pp. 26-32). Xalapa: Universidad Veracruzana.

Rama, Á. (1986b). El boom en perspectiva. En La novela en América Latina. Panoramas 1920-1980 (pp. 235-293). Xalapa: Universidad Veracruzana.

Ramb, A. M. (2011). De cómo Osvaldo Bayer nos salvó en dictadura. En J. Ferrer (Ed.), Osvaldo Bayer por otras voces (pp. 105-110). $2^{\text {a }}$ ed. corregida y ampliada. La Plata: Universidad Nacional de La Plata. Rodríguez, E. (1963). El mundo mágico de Carlos Fuentes. Número, 2a época, (2). 144-159.

Rodríguez, E. (1984). The Boom: a Retrospective. Interview by Alfred J. Mac Adam. Review: Literature and Arts of the Americas, 17(33), 30-36.

Saccomanno, G. (10 de octubre de 2004). Desde los 60. Página 12. Recuperado de https://www.pagina12.com.ar/diario/suplementos/libros/10-1258-2004-10-15.html 
Setti, R. A. (1989). Sobre la vida y la política: Diálogo con Vargas Llosa. San José: Kosmos.

Solares, I. (1982). Entrevista con Mario Vargas Llosa. Vuelta, 6(67), 26-29.

Tejera, M. J. (2001). Literatura y dialéctica. En A. Revueltas y P. Cheron (Eds.), Conversaciones con José Revueltas (pp. 43-53). México: Era.

Vargas, M. (1968). Cinco miradas sobre Cortázar. Buenos Aires: Tiempo Contemporáneo.

Vargas, M. (1970). Luzbel, Europa y otras conspiraciones. En Literatura en la revolución y revolución en la literatura. Polémica (pp. 78-93). México: Siglo XXI.

Vargas, M. (1993). El pez en el agua. Memorias. México: Seix Barral.

Vargas, M. (2000). La guerra del fin del mundo. México: Alfaguara.

Vargas, M. (3 de octubre de 2002). Aristóteles y el Padre Simeón. Piedra de toque. Caretas. Recuperado de http://www.caretas.com.pe/2002/1741/columnas/mvll.phtml

Vargas, M. (2004). La tentación de lo imposible. Victor Hugo y Los Miserables. Madrid: Alfaguara.

Vargas, M. (2009). Sables y utopías. Visiones de América Latina. Montevideo: Aguilar.

Vallejo, R. (2014). Cortázar, revolú-cronopio-nario. Kipus. Revista Andina de Letras, (36). 25-46.

Vilela, S. (27 de octubre de 2013). Los otros desvelos de un escritor. La Tercera. Recuperado de https://www.latercera.com/noticia/los-otros-desvelos-de-un-escritor/ 